\section{Revista de CIENCIAS AMBIENTALES Tropical Journal of Environmental Sciences}

\title{
Impacto de un pasivo ambiental petrolífero en el área y flora vascular a orillas del lago Titicaca, Perú
}

\author{
Impact of a petroleum environmental liability in the area and vascular flora on the \\ shores of Lake Titicaca, Peru
}

\author{
Dennis X. Huisa B. ${ }^{1}$, Alfredo L. Loza-Del Carpio ${ }^{2}$
}

[Recibido: 19 de noviembre 2020, Aceptado: 8 de mayo 2021, Corregido: 28 de mayo 2021, Publicado: 1 de julio 2021]

\section{Resumen}

[Introducción]: Por décadas, petróleo crudo en emulsión con aguas de formación discurrieron desde un pasivo ambiental petrolífero a orillas del lago Titicaca; [Objetivo]: planteándose estimar la superficie terrestre afectada y degradada por dicha fuente contaminante y determinar su efecto en la flora y vegetación silvestre en Ahuallani, $\mathrm{Pu}-$ no-Perú. [Metodología]: Se delimitó el área mediante imágenes Landsat, diferenciándose zonas de mayor o menor impacto mediante software QGIS, georreferenciándose los bordes del área in situ; se evaluó la flora y vegetación con cuadrantes de $1 \mathrm{~m}^{2}$ distribuidos aleatoriamente, los datos se analizaron mediante índices de diversidad Shannon-Wiener, Simpson y Jaccard, y prueba de Kruskall Wallis según zonas homogéneas. [Resultados]: El área total afectada alcanzó 96.54 ha, de las cuales en 94.8 ha (98.2 \%) conformaron una zona de dispersión (ZD) del fluido contaminante, donde se diferenció una superficie degradada de 29.7 ha con absoluta ausencia de vegetación y otra área de halófitas de 65.1 ha. Se diferencia además una zona circundante al pozo desde donde brotaba el petróleo crudo (ZP) y una zona del canal (ZC), ambas conformaron el $1.8 \%$ del área afectada. Mayor diversidad florística presentó la ZP con 22 especies, el área de halófitas sólo presentó tres; la densidad fue estadísticamente similar con 30.33 plantas $/ \mathrm{m}^{2}$ para la ZP, 20.33 plantas $/ \mathrm{m}^{2}$ para ZC y 13.67 plantas $/ \mathrm{m}^{2}$ para el área de halófitas. Así mismo, para ZP el $H^{\prime}=0.90 \pm 0.33$ a y la $D=0.72 \pm 0.13$, para ZC el $H^{\prime}=0.90 \pm 0.33$ a y la $D=0.67 \pm 0.15$, finalmente para ZD el $H^{\prime}$ $=0.16 \pm 0.11 \mathrm{~b}$ y la $D=0.49 \pm 0.10$, según $J$ ' ZP y ZD (19.35\% similitud), y la densidad vegetacional $\mathrm{ZD}=30.33$, ZC $=20.33$ y ZD $=13.67$. [Conclusiones]: Resaltando en esta última la abundancia natural de Sarcocornia pulvinata, con potencial valor para implementar estrategias de fitorremediación en la localidad.

Palabras clave: Aguas de formación; área afectada; contaminación; halófitas; petróleo.

\section{Abstract}

[Introduccion]: By decades, crude oil in emulsion with formation waters flowed from petroleum environmental liability on shores of Titicaca lake, [Objective]: Before it was raised to estimate the land surface affected and degraded by said polluting source and determine its effect on the flora and vegetation in Ahuallani, Puno-Peru. [Methodology]: Area was delimited by Landsat images, differentiating areas of greater or lesser impact using QGis software, georeferencing later the edges of the area in situ; flora and vegetation were evaluated with $1 \mathrm{~m}^{2}$ quadrants distributed randomly, data were analyzed using diversity indices and the Kruskall Wallis test according to homogeneous zones. [Results]: Total affected area reached 96.54 ha, of which 94.8 ha $(98.2 \%)$ formed a dispersal zone

1 Investigador, Asociación para la Conservación de Biodiversidad ACB-PRO CARNIVOROS, Egresado de la Facultad de Ciencias Biológicas de Universidad Nacional del Altiplano Puno, Perú; dennis.bhd@gmail.com, https://orcid.org/0000-0002-3314-9149

2 Profesor, Programa de Ecología de la Universidad Nacional del Altiplano Puno, Perú; aloza@edu.gob.pe, https://orcid. org/0000-0003-4915-1152

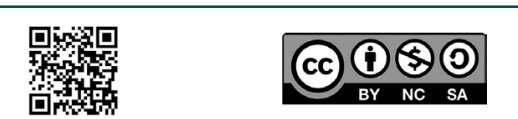
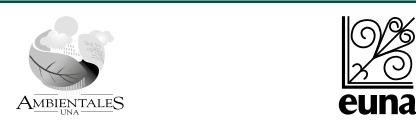


\section{Revista de CIENCIAS AMBIENTALES Tropical Journal of Environmental Sciences}

Revista de Ciencias Ambientales (Trop J Environ Sci) e-ISSN: 2215-3896

(Julio-Diciembre, 2021) . Vol 55(2): 180-196 DOI: https://doi.org/10.15359/rca.55-2.9 Open Access: www.revistas.una.ac.cr/ambientales e-mail: revista.ambientales@una.ac.cr Huisa D. y Loza-Del Carpio A.

(ZD) of the contaminating fluid, where a degraded surface of 29.7 ha was distinguished with absence absolute of vegetation and another halophytes area of $65.1 \mathrm{ha}$. Also differentiates a surrounding area the hole from which the crude oil gushed out (ZP) and a channel area (ZC) through which it flowed to ZD, both conformed $1.8 \%$ of the affected area. Floristic diversity greater showed ZP with 22 species, the halophyte area only presented three: Density was statistically similar with 30.33 plants $/ \mathrm{m}^{2}$ for ZP, 20.33 plants $/ \mathrm{m}^{2}$ for ZC and 13.67 plants $/ \mathrm{m}^{2}$ for the halophyte area. Likewise, for $\mathrm{ZP}$ the $\mathrm{H}^{\prime}=0.90 \pm 0.33 \mathrm{a}$ and the $\mathrm{D}=0.72 \pm 0.13$, for $\mathrm{ZC}$ the $\mathrm{H}^{\prime}=0.90 \pm 0.33 \mathrm{a}$ and the $\mathrm{D}=0.67$ \pm 0.15 , finally for $\mathrm{ZD}$ the $\mathrm{H}^{\prime}=0.16 \pm 0.11 \mathrm{~b}$ and the $\mathrm{D}=0.49 \pm 0.10$, according to $\mathrm{J}$ ' $\mathrm{ZP}$ and $\mathrm{ZD}(19.35 \%$ similarity), and the vegetation density $\mathrm{ZD}=30.33, \mathrm{ZC}=20.33$ and $\mathrm{ZD}=13.67$. [Conclusions]: Highlighting in it natural abundance of Sarcocornia pulvinata, with potential value to implement phytoremediation strategies in the locality.

Keywords: Affected area; halophytes; petroleum; pollution; water formation.

\section{Introducción}

Al noroeste del lago Titicaca, sobre los 3900 metros de altitud, se encontraban las zonas petrolíferas de mayor altitud en el mundo (Newell, 1949). Durante las primeras perforaciones extractivas en 1875 por la Compañía Corocoro, se halló petróleo a tan solo $122 \mathrm{~m}$ de profundidad, (PERUPETRO, 2008). Luego, desde 1905 “Titicaca Oil Company” realizó una serie de perforaciones de exploración. ocho de ellos fueron productivos hasta 1911, luego, se cedieron concesiones a otras empresas (Sociedad de Petróleo España, Peruvian Corporation, entre otras) cuyos resultados infructuosos propiciaron el abandono de todos los trabajos en 1925; posteriormente, desde 1939 hasta pasado el siglo XX, otras empresas estuvieron interesadas en la explotación del petróleo (el mismo estado peruano, Texaco, Yugansk Petro Andes, Yukos, Siboil Perú), pero sus actividades tampoco evidenciaron beneficios comerciales (PERUPETRO, 2008).

Sin embargo, por las cantidades más importantes producidas entre 1906 y 1925 (35 mil tn) desde ocho pozos (Newell, 1949) y por las actividades subsecuentes a los diferentes procesos de exploración, quedaron pasivos ambientales, cuyos impactos se perciben hasta la actualidad. La ausencia de un plan de cierre al concluir las actividades de exploración y explotación, el abandono institucional y el deficiente sellado de los pozos de los que permanentemente emanaban aguas salitrosas con derrames de petróleo crudo, transgredieron la integridad ecológica del lago Titicaca y de los ecosistemas terrestres adyacentes con riesgos considerables para los recursos naturales y la biodiversidad (Martínez et al, 2007). Incluso, la operación multisectorial, precedida por PERÚPETRO para el sellado permanente de estos pozos contaminantes en el 2008 (PERUPETRO, 2008), tampoco logró controlar los efectos sobre el lago Titicaca y su entorno, percibiéndose al presente una amplia área terrestre afectada, con escasa vegetación natural e inutilizada para la actividad agropecuaria.

Evidentemente, el sector más afectado incluye las localidades de Pirín y Ahuallani, que abarca parte de la zona de amortiguamiento de la Reserva Nacional del Titicaca, donde los derrames de petróleo crudo y aguas de formación por décadas, deterioraron una extensa superficie de suelos adyacentes al ecosistema lacustre, desde un pozo deficientemente cerrado denominado RH-10. Una evaluación previa al sellado de dicho pozo registró que estos fluidos que discurrían hacia el lago Titicaca, atravesando el área terrestre, presentaban un $\mathrm{pH}$ de hasta 9.05, fenoles

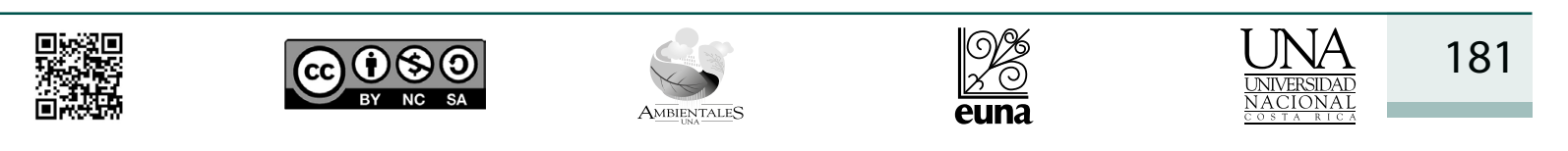




\section{Revista de CIENCIAS AMBIENTALES Tropical Journal of Environmental Sciences}

Revista de Ciencias Ambientales (Trop J Environ Sci)

e-ISSN: 2215-3896

(Julio-Diciembre, 2021) . Vol 55(2): 180-196

DOI: https://doi.org/10.15359/rca.55-2.9

Open Access: www.revistas.una.ac.cr/ambientales e-mail: revista.ambientales@una.ac.cr Huisa D. y Loza-Del Carpio A.

$0.004 \mathrm{mg} / \mathrm{L}$, metales pesados como cadmio hasta $0.008 \mathrm{mg} / \mathrm{L}$ y mercurio entre 0.0005 a 0.0026 mg/L (Machaca, 2007); además, las aguas de formación pueden alcanzar una DBO (Demanda Bioquímica de Oxígeno) promedio de $595 \mathrm{mg} / \mathrm{L}$, DQO (Demanda Química de Oxígeno) entre 880 y $2036 \mathrm{mg} / \mathrm{L}$, conductividad eléctrica entre 1275 a $3565 \mathrm{u} / \mathrm{cm}$ y suelen contener metales adicionales como arsénico, bario, cromo, plomo, cobre, zinc, compuestos orgánicos como bencenos, hidrocarburos de petróleo en emulsión, y otros elementos potencialmente tóxicos como sulfuros, cloruros sólidos suspendidos, grasas, sulfuro de hidrógeno, entre otros (Ogbonna et al., 2009; Neff et al., 2011). Todos estos elementos tienen peligrosos efectos en la salud humana, la biodiversidad, el suelo, el agua y en actividades económicas como la agricultura (Gay et al., 2010; Rodríguez-Eugenio et al., 2019); además los hidrocarburos aromáticos policíclicos tienen alta capacidad mutagénica y carcinógena (Rodríguez-Eugenio, 2019), estando los pobladores del lugar permanentemente expuestos a estas peligrosas situaciones.

Pero el efecto percibido, en gran parte del área, como más destacable es su aspecto desértico y ausencia de vegetación casi total, que contrasta notablemente del resto del área natural; apreciándose zonas con afloramientos salinos y amplias áreas de tonalidad rojo naranja, denotando elevadas concentraciones de sal en el suelo. Las aguas de formación como las que brotaron de los pozos tienen una concentración de sal entre 10 y $150 \mathrm{~g} / \mathrm{L}$, además de bicarbonatos, sulfatos, calcio (Tuset, 2020), niveles suficientes para afectar las propiedades fisicoquímicas del suelo, el equilibrio ecológico del área y limitar fuertemente el crecimiento de la mayoría de plantas (Shrivastava y Kumar, 2015). Aunque, algunas especies vegetales han desarrollado mecanismos para crecer en suelos salinos, e incluso pueden prosperar en suelos contaminados por un proceso de salinización antrópica (Badia, 1992), por lo que estas suelen ser las especies propicias para restaurar dichos hábitats como entes de fitorremediación (Guida-Johnson et al., 2017) y justamente, en este ámbito de Ahuallani, algunas especies vegetales que podrían ser utilizadas posteriormente con fines de restauración han prosperado relativamente..

Se desconoce el área total de suelos afectada por el pasivo ambiental y sus derrames contaminantes, y también, si existe un proceso de restauración pasiva natural propiciada por una sucesión secundaria a partir de vegetación halófita tolerante a estas nuevas condiciones del suelo y cuáles serían estas especies. Para recuperar suelos contaminados y establecer medidas de remediación es necesario conocer previamente la superficie afectada, caracterizar el sitio y la cubierta vegetal establecida (Chan-Quijano et al., 2015) y cuando se pretende aplicar una estrategia de fitorremediación es necesario identificar las especies tolerantes a las nuevas condiciones (Yavari et al., 2015). Por ello, el presente estudio posibilitaría establecer los criterios básicos para una propuesta de restauración de este hábitat degradado, ya que, si estos problemas de salinidad y contaminación de suelos no se solucionan de inmediato, los peligros potenciales pueden tardar décadas y seguir manifestándose con efectos de gran magnitud en el ecosistema y la salud pública (Sabroso y Pastor, 2004). En este contexto, es que la presente investigación se plantea como objetivo evaluar el área afectada por un pasivo ambiental petrolífero a orillas del lago Titicaca y su impacto en la flora vascular en Ahuallani, Puno, Perú.

\begin{tabular}{|c|c|c|c|c|c|}
\hline 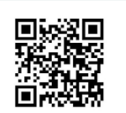 & (c) & $\underbrace{}_{\text {AMBIFNAIIES }}$ & $\begin{array}{l}\frac{9 \%}{2} \\
\frac{2}{2} \\
\text { euna }\end{array}$ & $\frac{\text { UNA }}{\frac{\text { UNIVERIDAD }}{\text { NACIONAL }}}$ & 182 \\
\hline
\end{tabular}




\section{Revista de CIENCIAS AMBIENTALES Tropical Journal of Environmental Sciences}

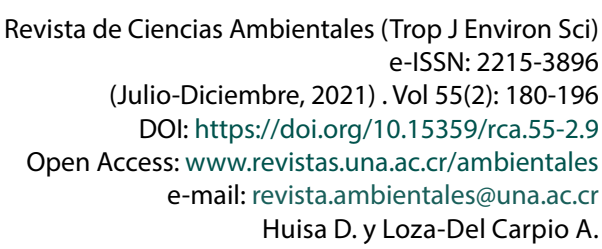

Revista de Ciencias Ambientales (Trop J Environ Sci) e-ISSN: 2215-3896

(Julio-Diciembre, 2021) . Vol 55(2): 180-196 DOI: https://doi.org/10.15359/rca.55-2.9 Open Access: www.revistas.una.ac.cr/ambientales e-mail: revista.ambientales@una.ac.cr Huisa D. y Loza-Del Carpio A.

\section{Metodología}

\section{1 Área de estudio}

La investigación se circunscribió a la zona influenciada por los afluentes contaminantes de la perforación RH-10, a orillas del lago Titicaca y Zona de Amortiguamiento de la RNT (Reserva Nacional del Titicaca), en el sector Ahuallani, distrito de Pusi y provincia de Huancané de la

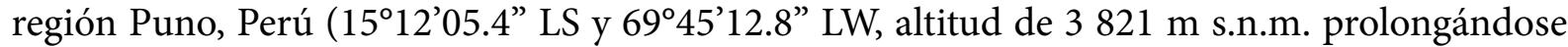
hasta los $3890 \mathrm{~m}$ s.n.m.) (Figura 1). Las temperaturas en el sector tienen una amplitud de -5 hasta $15^{\circ} \mathrm{C}$ y una precipitación media anual de $650 \mathrm{~mm}$ (SENAMHI, 2015). Predomina la actividad agrícola con cultivos de papa, quinua, avena y cebada, así como crianzas de ganado ovino, porcino y vacuno.

\subsection{Estimación de la superficie afectada}

Para establecer los límites del área impactada con evidencia del impacto por las aguas de formación y petróleo crudo, se utilizaron imágenes satelitales de Google Satellite basemap adjunta a QGIS 3.14.10, supervisándose y georreferenciando el área afectada mediante caminatas por el perímetro (cada $20 \mathrm{~m}$ ), considerando en la delimitación superficies ausentes de vegetación o con vegetación diferente a la de inmediaciones y áreas de dispersión de sales y pedruscos salitrosos. En total, se georreferenciaron 631 puntos mediante GPS Garmin e-trex 20, proyección Universal Transversal Mercator (UTM) y procesados con los softwares QGIS 3.4.10 y Google Satellite basemap, considerando además Cartas Nacionales del Perú de la Zona 19 y datum World Geodetic System 1984 (WGS-84). Esta fase se realizó durante noviembre a diciembre de 2015, indicando que la cota del lago se encontraba por debajo del nivel histórico durante el registro de datos (3810 m s.n.m.), por lo que la georreferenciación abarcó parte del ámbito emergido del lago Titicaca.

El ámbito evaluado se zonificó en tres secciones de impacto según la distancia al punto de afloramiento del fluido petrolífero (Figura 1): ZP (Zona de Perforación) ubicación del pozo RH-10 del cual emanaban los efluentes contaminantes, ZC (Zona de Canal) confeccionado por los pobladores para dirigir las aguas al lago Titicaca y ZD (Zona de Dispersión) área hasta donde ingresaban las aguas del canal y se esparcían previo al ingreso al lago.

\begin{tabular}{|c|c|c|}
\hline 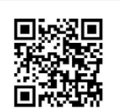 & 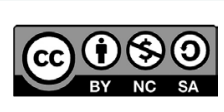 & 183 \\
\hline
\end{tabular}




\section{Revista de CIENCIAS AMBIENTALES Tropical Journal of Environmental Sciences}

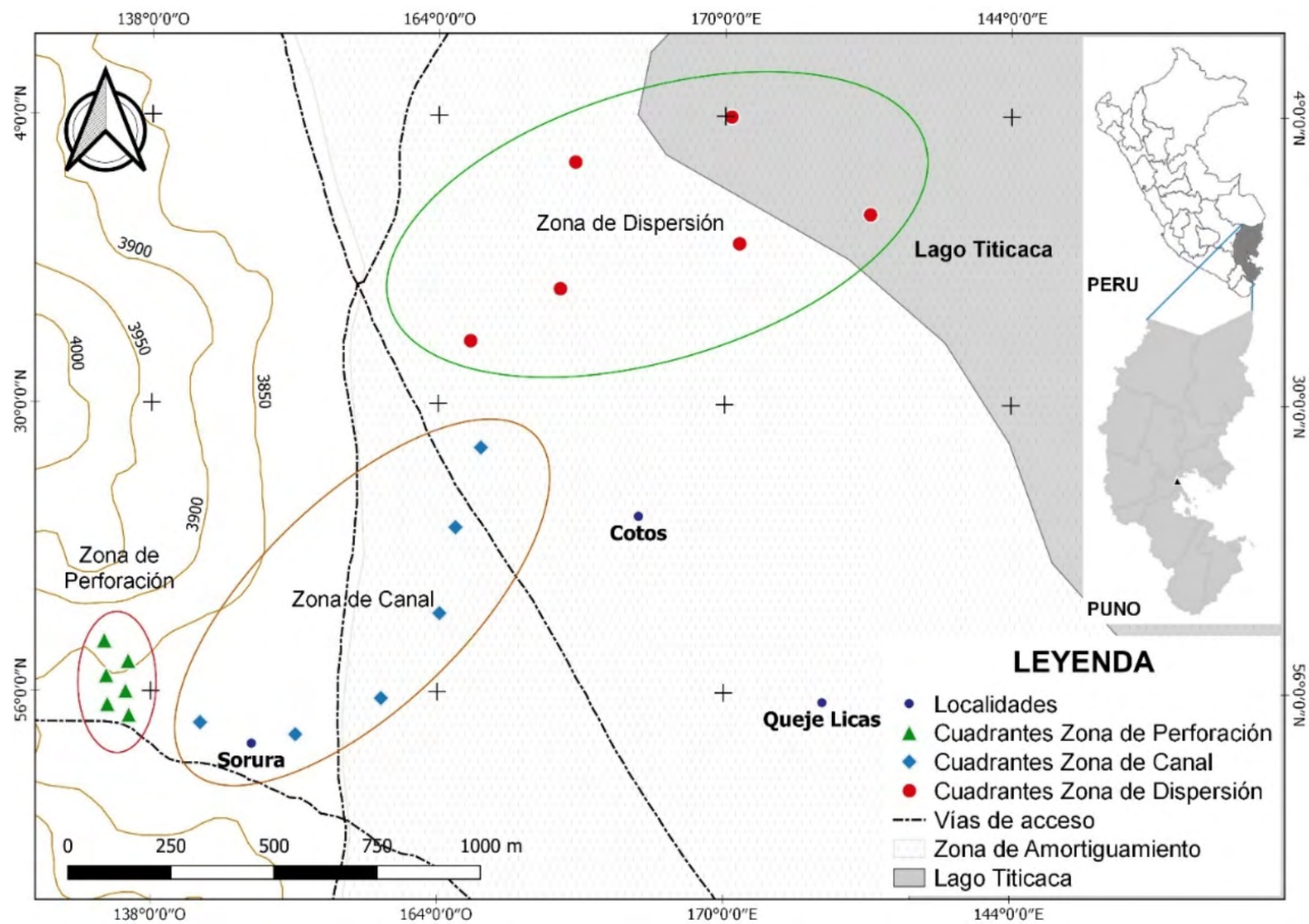

Figura 1. Área de estudio y puntos de muestreo de flora vascular en la localidad de Ahuallani (Pusi, Pirín), Puno, Perú. Figure 1. Study area and sampling points of vascular flora in the town of Ahuallani (Pusi, Pirín), Puno, Peru.

\subsection{Evaluación del impacto en la composición florística}

Llevada a cabo en la época lluviosa Ene-Mar de 2016, disponiendo cuadrantes aleatorios de $1 \mathrm{~m}^{2}$ dentro de los límites del área definida en la zonificación (ZP, ZC y ZD). Se evaluaron seis cuadrantes mensuales por zona, herborizando especímenes de flora encontrados dentro de ellos según metodología botánica convencional e identificándose las especies mediante claves como la de Pestalozzi et al. (1998) y Tropicos (2020), Base de Datos del Missouri Botanical Garden, confirmándose luego las identidades en el Herbario Sur Peruano (HSP) del Instituto Científico Michael Owen Dillon IMOD (Arequipa, Perú) en Ene-Mar del 2018.

Para el análisis de datos en la composición florística se determinó la abundancia relativa por cada zona, utilizando la siguiente Ecuación 1 (Salmerón et al., 2015):

$$
A R(\%)=N_{\mathrm{x}}{ }^{*} 100 / N_{\mathrm{t}}(\text { E. } 1)
$$

\begin{tabular}{|c|c|c|c|c|c|}
\hline 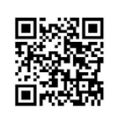 & (c) () () () & $\bigotimes_{\text {AMBEENTALS }}$ & $\begin{array}{l}\frac{9 \%}{2} \\
\frac{2}{2} \\
\text { euna }\end{array}$ & 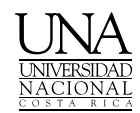 & 184 \\
\hline
\end{tabular}




\section{Revista de CIENCIAS AMBIENTALES Tropical Journal of Environmental Sciences}

Revista de Ciencias Ambientales (Trop J Environ Sci) e-ISSN: 2215-3896

(Julio-Diciembre, 2021) . Vol 55(2): 180-196

DOI: https://doi.org/10.15359/rca.55-2.9

Open Access: www.revistas.una.ac.cr/ambientales e-mail: revista.ambientales@una.ac.cr Huisa D. y Loza-Del Carpio A.

Donde:

$A R$ es la abundancia relativa de cada especie

$N_{\mathrm{x}}=$ número de individuos de la especie " $\mathrm{x}$ "

$N_{\mathrm{t}}^{\mathrm{x}}=$ número total de individuos de todas las especies.

Para la estimación del volumen de petróleo derramado $(V D)$ a partir de superficie de terreno afectado se usó el modelo determinístico propuesto por Mackay y Mohtadi (1975) Ecuación 2.

$$
V D=\frac{\sqrt[0.89]{A T A m^{2}}}{53.5}(\mathbf{E . 2})
$$

Donde:

$\mathrm{VD}=$ Volumen de petróleo demarrado.

ATA = área total afectada.

Además, del muestreo de flora se analizaron índices de dominancia de Simpson $(D)$, diversidad de Shannon-Wiener $\left(H^{\prime}\right)$, de similitud de Jaccard $\left(J^{\prime}\right)$ y se utilizó la prueba de Kruskall-Wallis para determinar diferencias en la diversidad de especies y densidad de la vegetación entre zonas. Los datos de $D, H^{\prime}$ y $J^{\prime}$ fueron procesados en el software PAST v3.0 y la prueba de Kruskall-Wallis mediante el SPSS v22.

\section{Resultados y discusión}

\subsection{Superficie terrestre afectada}

Un área total de 96.54 ha tienen la condición de ATA (Área Total Afectada) causadas por emisiones de agua de formación y petróleo crudo en la localidad de Ahuallani, condición revelada principalmente por la ausencia de vegetación en contraste con zonas adyacentes. De esta superficie, 94.8 ha $(98.20 \%)$ conforman la zona de dispersión, cubriendo unos $2100 \mathrm{~m}$ hasta la orilla del lago Titicaca, con una ausencia casi total de vegetación (excepto especies halófilas) y suelos de apariencia desértica de una tonalidad rojo amarillenta; la zona de canal abarcó una franja entre 1 a $3 \mathrm{~m}$ de área afectada en todo su trayecto haciendo un total de 1.49 ha (1.54\%), mientras que la zona de pozo sólo presentó 0.25 ha $(0.26 \%)$ de terreno afectado, en una circunferencia alrededor del pozo RH-10 con un radio de $10 \mathrm{~m}$ (Cuadro 1). Las características del área se muestran en la (Figura 2).

\begin{tabular}{|c|c|c|}
\hline 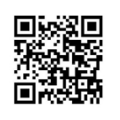 & (c) $\mathrm{BP}_{\mathrm{BY}}(\mathbf{\mathrm { N }}$ & 185 \\
\hline
\end{tabular}




\section{Revista de CIENCIAS AMBIENTALES Tropical Journal of Environmental Sciences}

Revista de Ciencias Ambientales (Trop J Environ Sci) e-ISSN: 2215-3896

(Julio-Diciembre, 2021) . Vol 55(2): 180-196 DOI: https://doi.org/10.15359/rca.55-2.9 Open Access: www.revistas.una.ac.cr/ambientales e-mail: revista.ambientales@una.ac.cr Huisa D. y Loza-Del Carpio A.

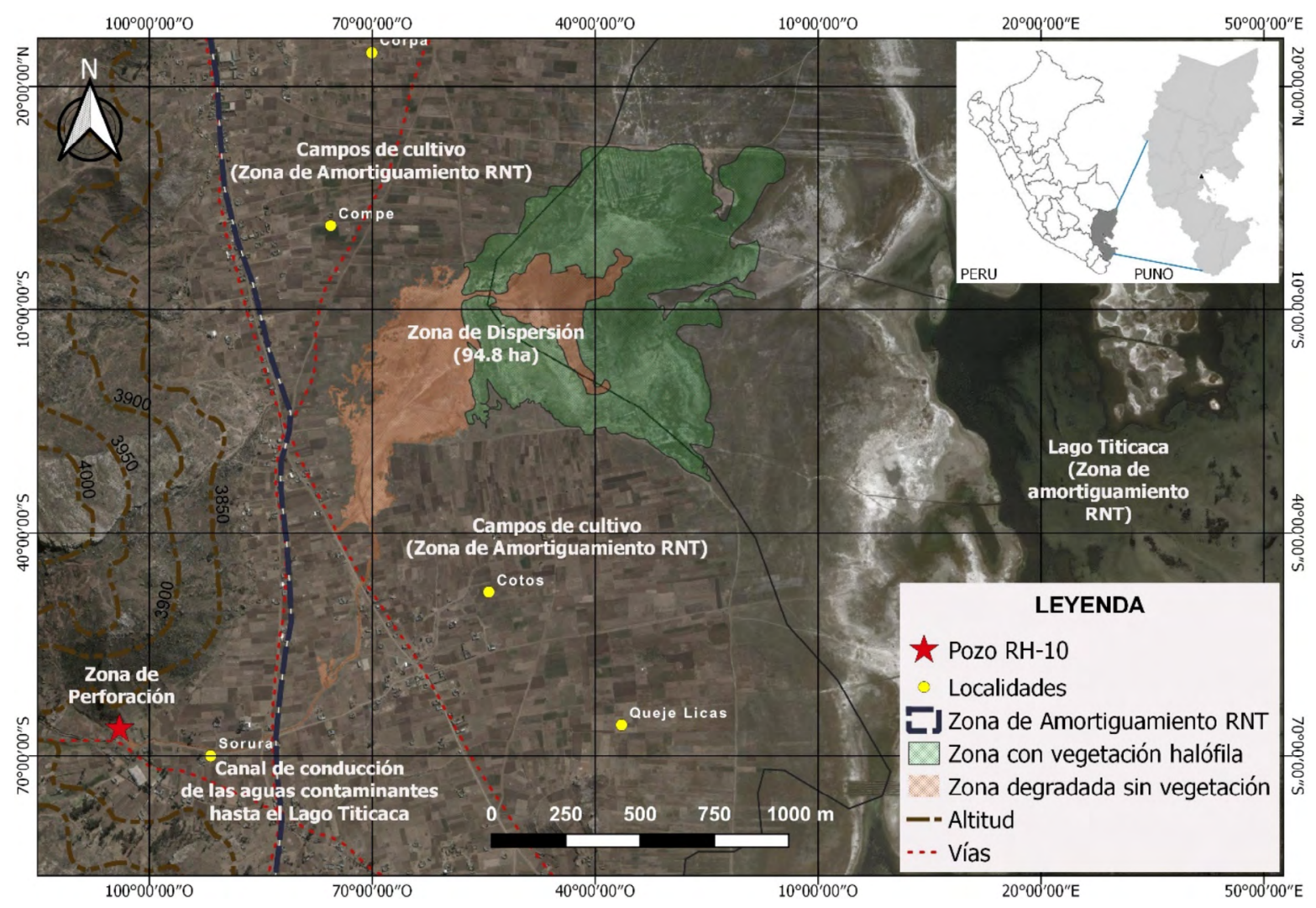

Figura 2. Imagen satelital con el detalle de las características del área afectada por efecto de fluidos petrolíferos desde la zona de perforación (pozo RH-10) en la localidad de Ahuallani, Puno, Perú.

Figure 2. Satellite image with the detail of the characteristics of the area affected by the effect of petroleum fluids from the drilling area (RH-10 well) in the town of Ahuallani, Puno, Peru.

Cuadro 1. Superficies afectadas por pasivo ambiental petrolífero en la localidad de Ahuallani, 2016, Puno, Perú. Table 1. Areas affected by oil environmental liabilities in the town of Ahuallani, 2016, Puno, Perú.

\begin{tabular}{|c|c|c|c|}
\hline \multirow{2}{*}{ Zonas } & \multicolumn{2}{|c|}{ Área } & \multirow{2}{*}{$\begin{array}{c}\text { Perímetro } \\
(\mathbf{k m})\end{array}$} \\
\hline & (ha) & $(\%)$ & \\
\hline Zona de perforación (ZP) & 0.25 & 0.26 & 0.28 \\
\hline Zona de canal (ZC) & 1.49 & 1.54 & 3.25 \\
\hline Zona de dispersión (ZD) & 94.8 & 98.2 & 11 \\
\hline Área degradada (ad) & 29.7 & 31.33 & 1.87 \\
\hline Área de halófitas (ah) & 65.1 & 68.67 & 9.13 \\
\hline Zona total afectada (ATA) & 96.54 & 100 & 14.53 \\
\hline Área afectada Zona de Amortiguamiento RNT & 96.04 & 99.48 & \\
\hline
\end{tabular}

(cc)




\section{Revista de CIENCIAS AMBIENTALES Tropical Journal of Environmental Sciences}

Revista de Ciencias Ambientales (Trop J Environ Sci) e-ISSN: 2215-3896

(Julio-Diciembre, 2021) . Vol 55(2): 180-196 DOI: https://doi.org/10.15359/rca.55-2.9 Open Access: www.revistas.una.ac.cr/ambientales e-mail: revista.ambientales@una.ac.cr Huisa D. y Loza-Del Carpio A.

A su vez, la zona de dispersión presentó dos áreas con características específicas: una desprovista totalmente de vegetación a la que se denominó "ad" (área degradada) con 29.7 ha (31.33 \%) (Figura 3.A) y la otra denominada "ah" (área de vegetación halófita), misma que por efecto de una restauración natural se ha establecido predominantemente la especie Sarcocornia pulvinata (R.E. Fr.) A.J. Scott que abarca 65.1 ha (68.67 \%) (Figura 3.C). Además, que gran parte del área total afectada se encuentra en la Zona de Amortiguamiento de la Reserva Nacional del Titicaca (RNT), abarcando 96.04 ha (99.48 \%) (Cuadro 1, Figura 2).

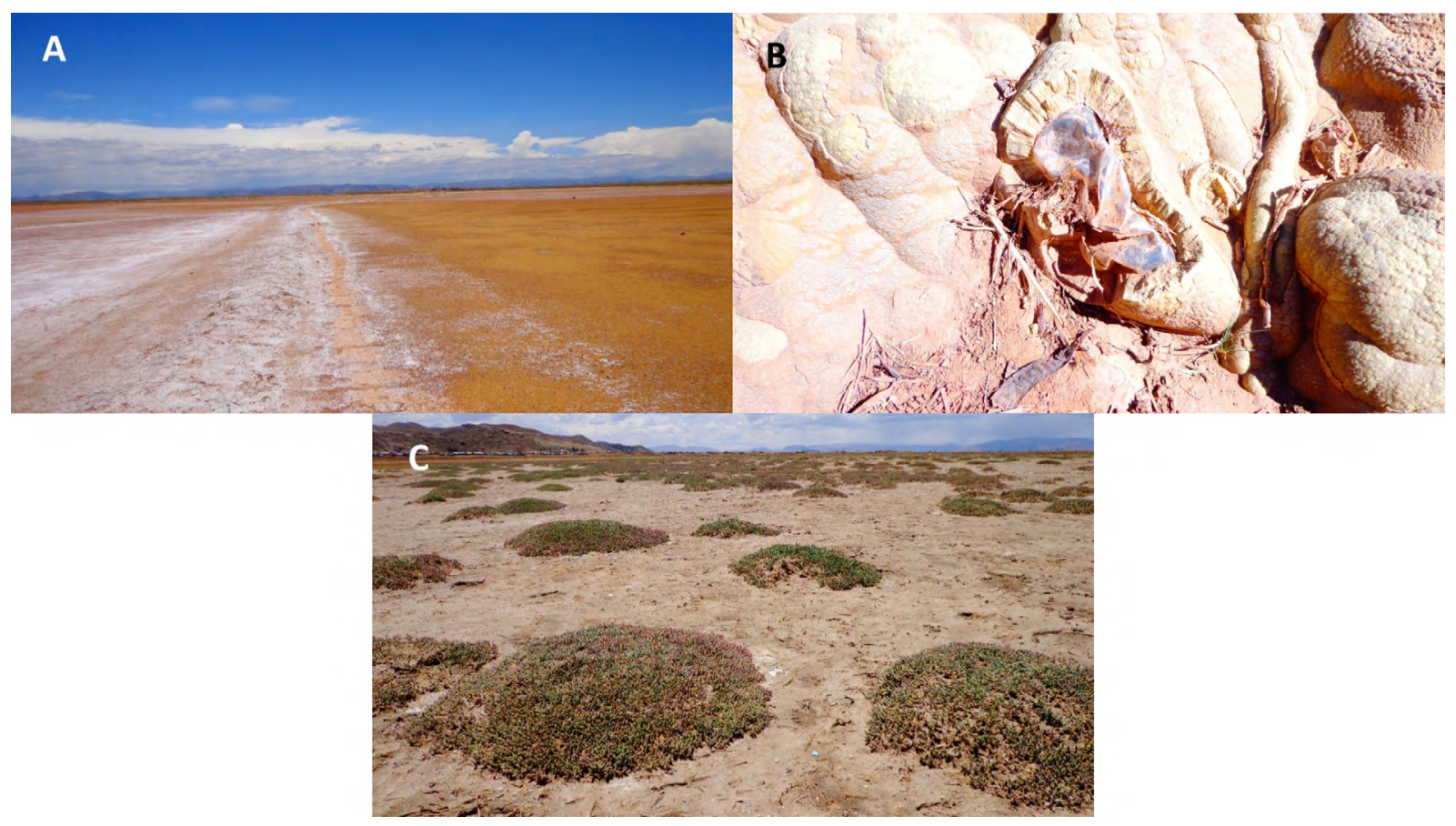

Figura 3. Condiciones del área afectada por pasivo de explotación petrolífera en la localidad de Ahuallani: A) área degradada (ad) sin vegetación, con apariencia desértica y afloramientos salinos. B) Fango petrificado en bordes de la zona del canal (ZC) y alrededor de diversos objetos. C) Vegetación halófita (Sarcocornia pulvinata) en la zona de dispersión (ZD).

Figure 3. Conditions of the area affected by oil exploitation liabilities in the town of Ahuallani: A) degraded area (ad) without vegetation, with a desert appearance and saline outcrops. B) Petrified mud on the edges of the canal zone (ZC) and around various objects. C) Halophyte vegetation (Sarcocornia pulvinata) in the dispersal zone (ZD).

Según el modelo determinístico propuesto por Mackay y Mohtadi (1975) se estima un derrame aproximado de $60592.61 \mathrm{~m}^{3}$ o el equivalente a 381116.19 barriles de petróleo en 83 años (desde 1925, año en que se abandonaron las labores de explotación, hasta el 2008 cuando se sellaron los pozos), lo que significa un vertimiento aproximado de 13 barriles diarios en todos esos años, que afectaron el área terrestre y obviamente volúmenes adicionales ingresaron también al lago Titicaca. Han ocurrido eventos de derrames de petróleo en el mundo en diferentes

\begin{tabular}{|c|c|c|}
\hline 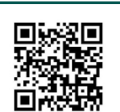 & (c) $\underset{\mathrm{BY}}{(i)} \mathrm{NC}_{\mathrm{SA}}$ & 187 \\
\hline
\end{tabular}




\section{Revista de CIENCIAS AMBIENTALES Tropical Journal of Environmental Sciences}

Revista de Ciencias Ambientales (Trop J Environ Sci)

e-ISSN: 2215-3896

(Julio-Diciembre, 2021) . Vol 55(2): 180-196

DOI: https://doi.org/10.15359/rca.55-2.9

Open Access: www.revistas.una.ac.cr/ambientales e-mail: revista.ambientales@una.ac.cr Huisa D. y Loza-Del Carpio A.

intensidades, como en el delta de Nigeria cuyos derrames se estiman de hasta 13 millones de barriles en 50 años (Kadafa, 2012) o como de 11200 barriles en unos días en Ecuador (Lafuente et al., 2019), con diferentes consecuencias ecológicas y en la salud pública, pero se desconoce este tipo de eventos y sus efectos a partir de pasivos ambientales en ámbitos altoandinos.

En el Perú, los derrames suelen ser frecuentes, principalmente en el norte y en el oriente amazónico (OEFA, 2020), la mayoría sin información específica al respecto, que incluya la amplitud del área afectada e implementación de acciones de recuperación. Por ejemplo, se tiene reportado que los derrames de petróleo crudo en una localidad de Loreto afectaron 0.26 ha de terrenos (OEFA, 2014), comparando con el área de Ahuallani, esta última es 370 veces mayor.

En otros ámbitos de Latinoamérica, los derrames de petróleo perjudicaron importantes extensiones de suelos productivos (Velásquez, 2017) y se han demostrado efectos nocivos en los ecosistemas y en la salud humana (Atubi, 2015). Por ejemplo, en Tabasco (México) 21244 ha de suelos fueron afectados a partir de 52 derrames, contaminando con hidrocarburos pastizales, bosques y zonas de cultivo (García-López et al., 2006); en Ecuador dañaron 30.3 ha de suelos con vegetación, riberas y zonas inundables (Jinés y Terán, 2010) y muchas veces los procesos de restauración no lograron recuperar las características físicas y químicas originales del suelo, tampoco, las comunidades de fauna de invertebrados, ni siquiera al cabo de 10 años (Trujillo-Narcia et al., 2012); en general, el terreno queda inhabilitado y estéril (Cavazos-Arroyo et al., 2014) y pueden provocar cuantiosas pérdidas económicas (Ojimba, 2011), situación que también acontecería en la localidad de Ahuallani. Además, los hidrocarburos del petróleo no son fácilmente degradables y se encuentran entre los contaminantes más peligrosos (Fowzia y Fakhruddin, 2018).

Aunque, en Ahuallani no se realizaron estudios específicos al respecto, son claramente perceptibles los efectos en el medio edáfico en un área de 96.54 ha, como un parche desértico extremo de tonos anaranjados dentro de una fisiografía dominantemente agrícola (Figura 2 y Figura 3.A); esta coloración, según Romero-Lázaro et al. (2019), está relacionada a derrames de soluciones ácido ferro cupríferas, como evidencia de contaminación residual. Asimismo, la permanente emisión de aguas de salmuera desde las aguas de formación como soluciones de cloruros de calcio y/o sodio emulsionados con el lodo y el aceite de petróleo (González-Partida et al., 2008; Schlumberger, 2020), conformaron bloques petrificados en los bordes de la zona del canal (Figura 3.B) y cuando hay presencia de hierro en las aguas de formación, este se combina con sulfatos y sustancias orgánicas formando lodo de hierro, especialmente en medios ácidos (MINAM, 2020), que suelen también endurecerse.

Actualmente, en Ahuallani la actividad agropecuaria se realiza alrededor del pasivo ambiental y numerosas viviendas rurales se establecen en sus inmediaciones, siendo un riesgo para la salud de las personas y para la calidad de sus productos, por lo que es necesario evaluar las condiciones del agroecosistema e implementar a la brevedad acciones de restauración de estos territorios; considerando que en otras latitudes (Nigeria por ejemplo) los derrames de petróleo han traído consecuencias irreparables por la contaminación de agua potable, degradación del

\begin{tabular}{|c|c|c|}
\hline 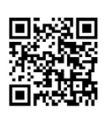 & (c) $\underset{\mathrm{BY}}{(\mathrm{NC}}(\mathrm{SA}$ & 188 \\
\hline
\end{tabular}




\section{Revista de CIENCIAS AMBIENTALES Tropical Journal of Environmental Sciences}

Revista de Ciencias Ambientales (Trop J Environ Sci) e-ISSN: 2215-3896

(Julio-Diciembre, 2021) . Vol 55(2): 180-196 DOI: https://doi.org/10.15359/rca.55-2.9 Open Access: www.revistas.una.ac.cr/ambientales e-mail: revista.ambientales@una.ac.cr Huisa D. y Loza-Del Carpio A.

recurso edáfico, pérdida de biodiversidad y de productividad, muerte y enfermedades en animales, así como el colapso de los ecosistemas en general (Kadafa, 2012; Atubi, 2015).

Los fluidos petrolíferos en Ahuallani también ingresaron todos esos años al ecosistema del lago Titicaca y son desconocidos sus efectos; aunque son probables importantes daños en las comunidades biológicas, teniendo en cuenta que el petróleo consume oxígeno y aumenta la DBO generando condiciones anóxicas en medios acuáticos (Velásquez, 2017), con efectos letales y subletales en peces (daño genético, malformaciones), además que los hidrocarburos se pueden bioacumular y transferir en la cadena trófica hasta el hombre (Yavari et al., 2015).

\subsection{Flora vascular}

Se registró un total de 33 especies de plantas vasculares asociadas a estos terrenos afectados (distribuidas en siete órdenes, 11 familias y 29 géneros), la mayor diversidad en la zona de perforación con 22 especies (55\%), luego la zona del canal con 15 especies (37.5\%) y finalmente la zona de dispersión con tan solo tres especies (7.5\%). En general, representa una baja diversidad comparada con estudios florísticos en áreas circundantes al lago Titicaca, como el de Gutiérrez y Canales (2012) que registraron 94 especies, por lo cual, se considera un indicio del efecto perjudicial que tuvo el pasivo petrolífero sobre la vegetación y la diversidad natural (Cuadro 2).

Cuadro 2. Riqueza de especies y promedios de abundancia relativa en la zona de perforación (ZP), zona de canal (ZC) y zona de dispersión (ZD), en el ámbito de impacto del pasivo ambiental petrolífero de Ahuallani. Letras diferentes entre columnas en el índice de Shannon indican diferencias significativas a la prueba de Tukey $(\mathrm{p}<0.05)$ Table 2. Species richness and averages of relative abundance in the drilling zone (ZP), channel zone (ZC) and dispersion zone (ZD), in the area of impact of the Ahuallani petroleum environmental liability. Different letters between columns in the Shannon index indicate significant differences to the Tukey test $(p<0.05)$

\begin{tabular}{|c|c|c|c|c|c|}
\hline \multirow{2}{*}{ Orden } & \multirow{2}{*}{ Familia } & \multirow{2}{*}{ Especie } & \multicolumn{3}{|c|}{ Abundancia relativa (\%) } \\
\hline & & & $\mathbf{Z P}$ & ZC & ZD \\
\hline \multirow[t]{10}{*}{ Asterales } & Asteraceae & Tagetes mandonii Sch. Bip. ex Klatt & 6.59 & 0 & 0 \\
\hline & & Tagetes multiflora Kunth & 14.29 & 0 & 0 \\
\hline & & Bidens andicola Kunth & 1.65 & 0 & 0 \\
\hline & & Tessaria sp. & 2.2 & 0 & 0 \\
\hline & & Viguiera procumbens (Pers.) S.F. Blake & 3.3 & 2.46 & 0 \\
\hline & & Chersodoma jodopappa (Sch. Bip.) Cabrera & 1.1 & 0 & 0 \\
\hline & & Baccharis tricuneata (L. f.) Pers. & 3.85 & 0 & 0 \\
\hline & & Grindelia boliviana Rusby & 0 & 0.82 & 0 \\
\hline & & Achyrocline alata (Kunth) DC. & 1.65 & 0 & 0 \\
\hline & & Grindelia sp. & 1.1 & 0 & 0 \\
\hline \multirow[t]{4}{*}{ Caryophyllales } & Cactaceae & Cumulopuntia boliviana (Salm-Dyck) F. Ritter & 12.64 & 0 & 0 \\
\hline & & Echinopsis maximiliana Heyder ex A. Dietr. & 0.55 & 16.39 & 0 \\
\hline & Polygonaceae & Rumex cuneifolius Campd. & 0 & 17.21 & 0 \\
\hline & Amaranthaceae & Sarcocornia pulvinata (R.E. Fr.) A.J. Scott & 0 & 0 & 58.54 \\
\hline
\end{tabular}

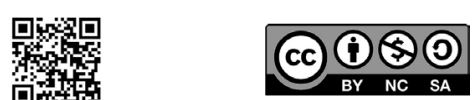

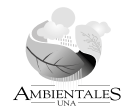




\section{Revista de CIENCIAS AMBIENTALES Tropical Journal of Environmental Sciences}

Revista de Ciencias Ambientales (Trop J Environ Sci) e-ISSN: 2215-3896

(Julio-Diciembre, 2021) . Vol 55(2): 180-196 DOI: https://doi.org/10.15359/rca.55-2.9 Open Access: www.revistas.una.ac.cr/ambientales e-mail: revista.ambientales@una.ac.cr Huisa D. y Loza-Del Carpio A.

\begin{tabular}{|c|c|c|c|c|c|}
\hline \multirow{2}{*}{ Orden } & \multirow{2}{*}{ Familia } & \multirow{2}{*}{ Especie } & \multicolumn{3}{|c|}{ Abundancia relativa (\%) } \\
\hline & & & ZP & ZC & ZD \\
\hline \multirow[t]{4}{*}{ Fabales } & Fabaceae & Astragalus arequipensis Vogel & 1.65 & 0 & 0 \\
\hline & & Cassia hookeriana Gillies ex Hook. \& Arn. & 11 & 0 & 0 \\
\hline & & Trifolium repens $\mathrm{L}$. & 1.65 & 0 & 0 \\
\hline & & Trifolium amabile Kunth & 0 & 7.38 & 0 \\
\hline \multirow[t]{2}{*}{ Lamiales } & Plantaginaceae & Plantago australis Lam. & 0 & 2.46 & 0 \\
\hline & Verbenaceae & Verbena hispida Ruiz \& Pav. & 2.2 & 0 & 0 \\
\hline Myrtales & Myrtaceae & Eucalyptus globulus Labill. & 1.1 & 0 & 0 \\
\hline \multirow[t]{10}{*}{ Poales } & Poaceae & Festuca dolichophylla J. Presl & 1.65 & 2.46 & 0 \\
\hline & & Bothriochloa sp. & 0 & 3.28 & 0 \\
\hline & & Aristida peruviana Beetle & 0 & 17.21 & 3.66 \\
\hline & & Calamagrostis rigescens (J. Presl) Scribn. & 0 & 10.66 & 0 \\
\hline & & Calamagrostis ovata (J. Presl) Steud. & 0 & 3.28 & 0 \\
\hline & & Chondrosum simplex (Lag.) Kunth & 0.45 & 2.46 & 0 \\
\hline & & Poa sp. & 0 & 0 & 37.8 \\
\hline & & Hordeum muticum J. Presl & 0 & 8.2 & 0 \\
\hline & & Poa аппиа $\mathrm{L}$. & 0.55 & 0 & 0 \\
\hline & & Jarava ichu (Ruiz \& Pav.) Kunth & 23.63 & 4.92 & 0 \\
\hline \multirow[t]{2}{*}{ Rosales } & Rosaceae & Tetraglochin cristatum (Britton) Rothm. & 3.85 & 0 & 0 \\
\hline & Rhamnaceae & Colletia spinosissima J.F. Gmel. & 3.3 & 0 & 0 \\
\hline $\mathrm{N}^{\circ}$ Especies & & 33 & 22 & 15 & 3 \\
\hline Shannon $\left(H^{\prime}\right)$ & & & $1.28 \pm 0.34 \mathrm{a}$ & $0.90 \pm 0.33 \mathrm{a}$ & $0.16 \pm 0.11 \mathrm{~b}$ \\
\hline Simpson $(D)$ & & & $0.72 \pm 0.13$ & $0.67 \pm 0.15$ & $0.49 \pm 0.10$ \\
\hline Densidad vegeta & & & 30.33 & 20.33 & 13.67 \\
\hline
\end{tabular}

La zona de perforación presentó la mayor diversidad y la mayor abundancia en cuanto a vegetación, no siendo afectado considerablemente por el pasivo petrolífero, debido a que los flujos contaminantes no se diseminaron alrededor de la boca del pozo (ZP), sino más bien, discurrieron a través de un canal (ZC) hasta dispersarse por las orillas del lago Titicaca (ZD). Por la ZP prosperaron 22 especies, donde J. ichu predominó en abundancia (23.63\%), seguidos por $T$. multiflora (14.29\%) y la cactácea C. boliviana (12.64\%). Básicamente, esta área es una zona de ladera y estas especies suelen ser comunes en estos hábitats, quizás, además, toleran relativos niveles de contaminación, especialmente $J$. ichu que se desarrolla significativamente en condiciones de suelos afectados por pasivos mineros (Martínez, 2018). En la ZC, por donde discurrían las aguas contaminantes desde el pasivo, predominaron $R$. cuneifolius (17.21\%), A. peruviana $(17.21 \%)$ y E. maximiliana (16.39\%), desarrollándose principalmente a partir de distancias de $1 \mathrm{~m}$ desde el borde del canal, ya que el borde mismo carecía de vegetación.

En la ZD, área donde se esparcían ampliamente las aguas contaminantes desde el canal hasta ingresar incluso al lago Titicaca, solo desarrollaron tres especies predominado ampliamente $S$. pulvinata con $58.54 \%$, luego Poa sp con $37.8 \%$ y finalmente, A. peruviana con $3.66 \%$, destacando la alta adaptación que tuvo la primera especie ante las afectadas condiciones de esta zona, cuya importancia como planta fitorremediadora del género Salicornia ya ha sido reportada en suelos

\begin{tabular}{|c|c|c|c|c|c|}
\hline 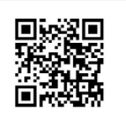 & (c) & $\underbrace{}_{\text {AMBIFNAIIES }}$ & $\frac{1 \% \%}{20}$ & $\frac{\text { UNA }}{\frac{\text { UNIVERIDAD }}{\text { NACIONAL }}}$ & 190 \\
\hline
\end{tabular}




\section{Revista de CIENCIAS AMBIENTALES Tropical Journal of Environmental Sciences}

contaminados para la eliminación de sal (Peña-Salamanca et al., 2013) y de selenio (Shrestha et al., 2006), así como en la absorción de diversos metales pesados desde relaves mineros, demostrándose esta eficiencia debido a su amplia proliferación natural en dichos terrenos (Sepúlveda et al., 2013), similar a como ocurre en Ahuallani. También, se ha reportado el potencial como fitorremediadores a especies del género Poa en suelos contaminados, debido a su capacidad bioacumuladora y como fitoestabilizadores de mercurio (Voijant et al., 2011), por lo que la poácea desarrollada en la ZD de Ahuallani pudiera tener similar capacidad.

Según el índice de diversidad $H^{\prime}$, todas las zonas alcanzan una pobre riqueza de especies, aunque la $\mathrm{ZP}$ presenta la más alta diversidad (1.28), luego la ZC (0.90) y finalmente la ZD cuya diversidad es sumamente baja (0.16), siendo esta última significativamente menor a las otras zonas según prueba de Kruskall Wallis $\left(\mathrm{H}_{\mathrm{GL}}{ }^{2}\right.$ $=6.16 ; \mathrm{p}<0.01)$ y Tukey $(\mathrm{p}<0.05)$. También, se aprecia una alta dominancia por algunas especies según el índice $D^{\prime}$, en la ZP (0.72) predominan de J. ichu, T. multiflora y C. boliviana lo que confirma su importante nivel de adaptación a las condiciones de esta zona. En la ZC la dominancia (0.67) es para A. peruviana, $R$. cuneifolius y E. maximilana de entre las 15 especies presentes y finalmente en la ZD (0.49) no existe una dominancia marcada por alguna especie según el índica $D^{\prime}$ (Cuadro 2). Un estudio en áreas colindantes con el Titicaca reporta índices de $H^{\prime}$ promedio entre 1.93 y 2.20 , mayores a lo encontrado en Ahuallani (Gutiérrez y Canales, 2012), lo que evidencia una consecuencia negativa sobre la diversidad florística en el área.

El índice de $J$ 'indica similitud en especies de 19.35 \% entre las zonas ZP y ZC y 5.88 \% entre las zonas ZC y ZD, las zonas ZD y ZP no tienen similitudes, el análisis clúster muestra que las tres zonas son distintas en cuanto a diversidad de especies, compartiendo un bajo número entre ellas, siendo relativamente semejantes las zonas ZC y ZP (Figura 4A), pero todas presentan un alto número de especies exclusivas considerando que la ZP presentó 15 especies exclusivas de 22 (68.2\%), la ZC ocho de 15 especies totales (53.3 \%) y la ZD dos de tres especies (66.7\%) (Figura 4B).
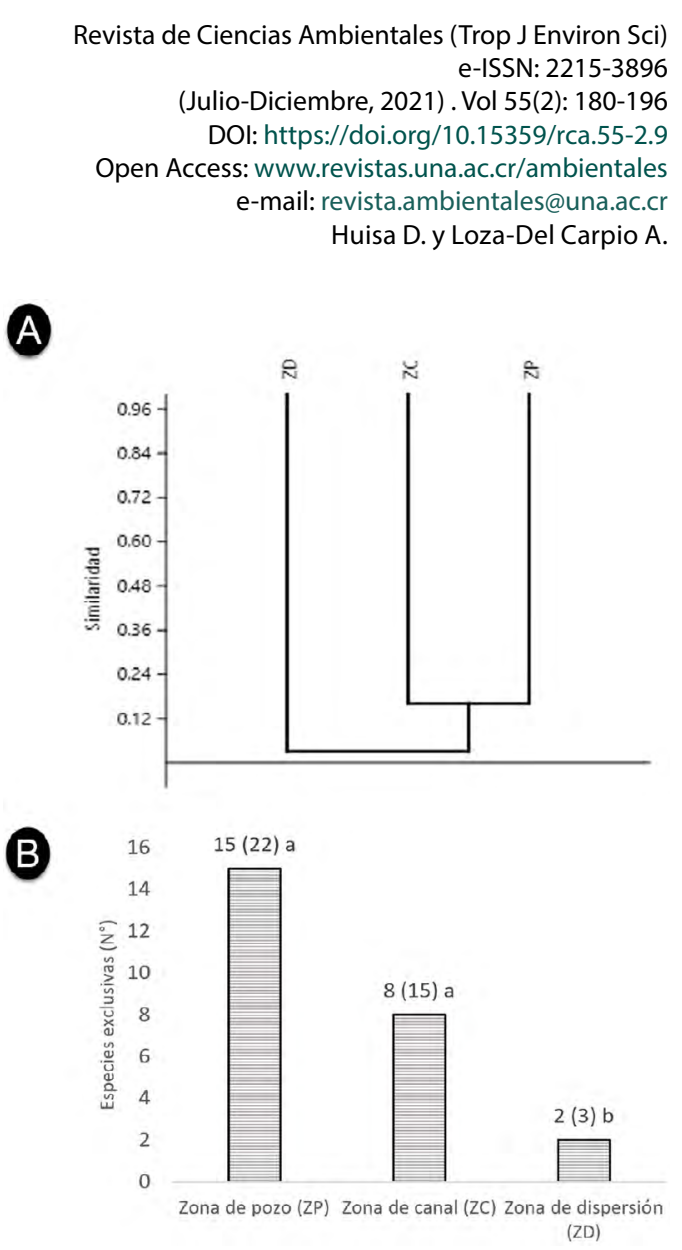

Figura 4. A) Diagrama clúster del índice de similitud de Jaccard $\left(J^{\prime}\right)$ para la diversidad de especies de flora entre zonas del área con impacto del pasivo petrolífero en Ahuallani. B) especies exclusivas por cada zona, del total de especies registradas, letras diferentes indican diferencias significativas según prueba de Tukey para la abundancia $(\mathrm{p}<0.05)$.

Figure 4. A) Cluster diagram of the Jaccard similarity index (J') for the diversity of flora species between zones of the area affected by the oil liability in Ahuallani. B) exclusive species for each area, of the total number of registered species, different letters indicate significant differences according to Tukey's test for abundance $(\mathrm{p}<0.05)$.

(c)




\section{Revista de CIENCIAS AMBIENTALES Tropical Journal of Environmental Sciences}

Revista de Ciencias Ambientales (Trop J Environ Sci)

e-ISSN: 2215-3896

(Julio-Diciembre, 2021) . Vol 55(2): 180-196

DOI: https://doi.org/10.15359/rca.55-2.9

Open Access: www.revistas.una.ac.cr/ambientales e-mail: revista.ambientales@una.ac.cr Huisa D. y Loza-Del Carpio A.

Aunque la diversidad florística fue mayor en las zonas de pozo y de canal, la densidad vegetacional fue similar en todas las áreas comparadas según la prueba de Kruskal-Wallis $\left(\mathrm{H}_{\mathrm{GL}}\right.$ $\left.{ }_{2}=2.09 ; \mathrm{p}<0.35\right)$. En la ZD, solo en el área de vegetación halófita (ah) prevaleció S. pulvinata con un promedio de $33 \pm 9.18$ plantas $/ \mathrm{m}^{2}$ y en el área degradada (ad) no se desarrolló ninguna planta. La ZP presentó la mayor densidad con $30.33 \pm 12.88$ plantas $\mathrm{m}^{2} /$ ha, seguido por la ZC con $20.33 \pm 8.37$ plantas $/ \mathrm{m}^{2}$ (Cuadro 2). Según estos resultados, el pasivo ambiental petrolífero también afectó severamente el desarrollo de plantas silvestres, especialmente en el área donde se dispersaron los fluidos contaminantes antes de su ingreso al lago, ya que el área misma del pozo e incluso la zona de canal por donde discurría, mostraron relativo desarrollo vegetacional; a diferencia de otras zonas cercanas a la localidad de Ahuallani, donde la densidad alcanzó un promedio de 178 plantas $/ \mathrm{m}^{2}$ (Vargas, 2002). En efecto, la contaminación de suelos por petróleo crudo puede restringir severamente el crecimiento de vegetación natural donde su biomasa apenas puede fluctuar entre 0 a $17.9 \mathrm{~g} / \mathrm{m}^{2}$ tal como ocurrió en otros ámbitos (Trujillo-Narcía et al., 2012) coincidiendo también con lo suscitado en Ahuallani (Cuadro 2).

\section{Conclusiones}

Las aguas de formación (salmuera petrolera) del Pozo RH-10 en el sector de Ahuallani (Pirín) a orillas del lago Titicaca, Puno, Perú afectaron una superficie de 96.54 ha, con un área totalmente degradada de 29.7 ha en las cuales no se desarrolla absolutamente ningún tipo de vegetación, aunque 65.1 ha evidencian un proceso natural de recuperación con el desarrollo de plantas halófitas especialmente $S$. pulvinata; y una pequeña área (1.74 ha) evidencia menor impacto con presencia de vegetación más diversa (alrededores del pozo y áreas adyacentes al canal de flujo). Casi toda el área afectada se encuentra en la zona de amortiguamiento de la RNT (99.48 \%) y está rodeada de fisiografía agrícola, poniendo en potencial riesgo la calidad de los productos, de los recursos naturales de áreas adyacente (totora, peces) que son utilizados directa e indirectamente (alimentación de ganado) en el consumo humano e incluso, pueden estar ocurriendo presuntos fenómenos de bioacumulación y biomagnificación por compuestos derivados de hidrocarburos. Por ello es imperativo implementar procesos de restauración.

De un total de 33 especies registradas en la zona afectada, 22 especies se presentaron en alrededores de la zona de pozo y 15 en la zona de canal, en cambio, la zona de dispersión presentó un área totalmente degradada sin ninguna especie y un área donde se adaptaron tres especies: La diversidad al índice de $H^{\prime}$ fue significativamente inferior en la zona de dispersión, pero la densidad fue estadísticamente similar en las tres zonas, destacándose en parte de esta última, una sustancial propagación de plantas halófitas. Aunque, la densidad en ningún caso fue mayor a 30.33 plantas $/ \mathrm{m}^{2}$ y comparado con otros estudios en áreas cercanas al Titicaca, la densidad supera las 100 plantas $/ \mathrm{m}^{2}$ lo que argumenta el efecto perjudicial que tuvo el pasivo ambiental sobre la vegetación natural. Se destaca el crecimiento y desarrollo natural en parte del área afectada de la amarantácea S. pulvinata cuyas densidades de 13.67 plantas $/ \mathrm{m}^{2}$ en un área de 65 ha mostrarían las posibilidades para su potencial aprovechamiento con fines de restauración.

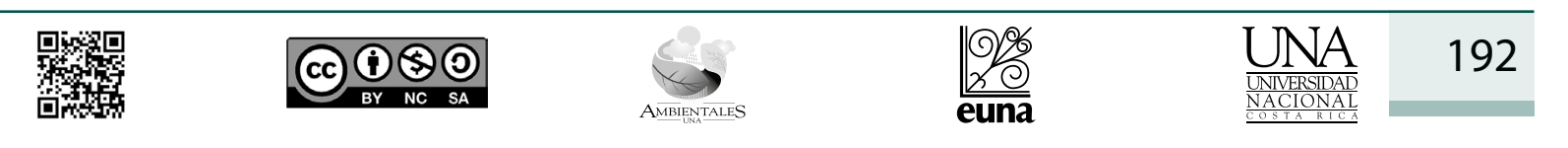




\section{Revista de CIENCIAS AMBIENTALES Tropical Journal of Environmental Sciences}

Revista de Ciencias Ambientales (Trop J Environ Sci)

e-ISSN: 2215-3896

(Julio-Diciembre, 2021) . Vol 55(2): 180-196

DOI: https://doi.org/10.15359/rca.55-2.9

Open Access: www.revistas.una.ac.cr/ambientales e-mail: revista.ambientales@una.ac.cr Huisa D. y Loza-Del Carpio A.

\section{5 Ética y conflicto de intereses}

Las personas autoras declaran que han cumplido totalmente con todos los requisitos éticos, tanto durante el estudio como en la producción del manuscrito; no hay conflicto de intereses de ningún tipo; que todas las fuentes financieras se mencionan completa y claramente en la sección de agradecimientos, y que están totalmente de acuerdo con la versión final editada del artículo.

\section{Agradecimientos}

Al Vicerrectorado de Investigación de la Universidad Nacional del Altiplano Puno y a Neotropical Grasland Conservancy NGC por los aportes en la subvención de la investigación, a los pobladores de la comunidad de Hatun Ayllu en Ahuallani por las facilidades prestadas durante las evaluaciones de campo y al equipo de PROCARNIVOROS que colaboraron en el proyecto. Finalmente, agradecemos a la revista y quienes de manera anónima dictaminaron y enriquecieron la versión final del escrito.

\section{Referencias}

Atubi, A. O. (2015). Effects of oil spillage on human health in producing communities of Delta State, Nigeria. European Journal of Business and Social Sciences, 4(08), 14 -30.

Badia. D. V. (1992). Suelos afectados por sales. Butlleti de la Societat Catalana de Ciencias, 13, 609-629. https://www.raco.cat/index.php/ButlletiSCFQMT/article/download/21859/302564

Cavazos-Arroyo, J., Pérez-Armendáriz, B., Mauricio-Gutiérrez, A. (2014). Afectaciones y consecuencias de los derrames de hidrocarburos en suelos agrícolas de Acatzingo, Puebla, México. Agricultura, Sociedad Y Desarrollo, 11, 539-550. https://doi.org/10.22231/asyd.v11i4.16

Chan-Quijano, J. G., Jarquín-Sánchez, A., Ochoa-Gaona, S., Martínez-Zurimendi, P., López-Jiménez, L. N., Lázaro-Vázquez, A. (2015). Directrices para la remediación de suelos contaminados con hidrocarburos. Teoría y Praxis, 17, 123-144. https://doi.org/10.22403/ UQROOMX/TYP17/05

Fowzia, A., Fakhruddin, A. N. (2018). A Review on environmental contamination of petroleum hydrocarbons and its biodegradation. International Journal of Environmental Sciences \& Natural Resources, 11(3), 70-74. https://juniperpublishers.com/ijesnr/pdf/IJESNR. MS.ID.555811.pdf

García-López, E., Zavala-Cruz, J., Palma-López, D. J. (2006). Caracterización de las comunidades vegetales en un área afectada por derrames de hidrocarburos. TERRA Latinoamericana, 24(1), 17-26.

Gay, J., Shepherd, O., Thyden, M., Whitman, M. (2010). The health effects of oil contamination: A compilation of research. Worcester Polytechnic Institute.

González-Partida, E., Camprubí, A., Canet, C., González-Sánchez, F. (2008). Fisicoquímica de salmueras e hidrocarburos en cuencas petroleras y en depósitos minerales tipo Mississippi

\begin{tabular}{|c|c|c|c|c|c|}
\hline 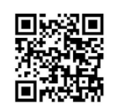 & (c) (i) $(9)$ & $\underset{\text { AMBENETILES }}{3}$ & $\frac{1 \%}{2 \%}$ & $\frac{\text { UNA }}{\frac{\text { UNIVERSIDAD }}{\text { NACIONAL }}}$ & 193 \\
\hline
\end{tabular}




\section{Revista de CIENCIAS AMBIENTALES Tropical Journal of Environmental Sciences}
Revista de Ciencias Ambientales (Trop J Environ Sci) e-ISSN: 2215-3896
(Julio-Diciembre, 2021) . Vol 55(2): 180-196 DOI: https://doi.org/10.15359/rca.55-2.9 Open Access: www.revistas.una.ac.cr/ambientales e-mail: revista.ambientales@una.ac.cr Huisa D. y Loza-Del Carpio A

Valley y asociados. Boletín de la Sociedad Geológica Mexicana, 60(1), 23-42. https://doi. org/10.18268/BSGM2008v60n1a3

Guida-Johnson, B., Abraham, E. M., Cony, M. A. (2017). Salinización del suelo en tierras secas irrigadas: perspectivas de restauración en Cuyo, Argentina. Revista de la Facultad de Ciencias Agrarias, 49(1), 205-215.

Gutiérrez, I. R., Canales, A. (2012). Evaluación comparativa de la diversidad de flora silvestre entre la isla taquile y el cerro chiani en relación a la altitud, Puno, Perú. Ecología Aplicada, 11(2), 39-46. https://doi.org/10.21704/rea.v11i1-2.424

Jinés, L., Terán, H. (2010). Evaluación del derrame de crudo de la línea de alta presión de pozo Sacha SA-78 en el oriente ecuatoriano, aplicando métodos analíticos de flujo en medios porosos (Ecuaciones de Darcy y Difusividad). Revista Tecnológica ESPOL - RTE, 23(1), 61-72.

Kadafa, A. A. (2012). Environmental impacts of oil exploration and exploitation in the Niger Delta of Nigeria. Global Journal of Science Frontier Research Environment \& Earth Sciences, 12(3), 19-28.

Lafuente W., Soto, L. M., López, C., Domínguez-Granda, L. (2019). Efectos de un derrame de petróleo crudo en la comunidad de macroinvertebrados bentónicos de un río amazónico ecuatoriano. Revista de Ciencias Ambientales, 53(1), 1-22. http://dx.doi.org/10.15359/rca.53-1.1

Mackay, D., Mohtadi, M. (1975). The Area Affected by Oil Spills on Land. The Canadian Journal of Chemical Engineering, 53, 140-143. https://doi.org/10.1002/cjce.5450530127

Machaca, N. C. (2007). Diagnóstico y gestión ambiental del pozo Aguallani en el lote S2 Puno Perú. [Tesis de maestría]. Universidad Nacional del Altiplano Puno. Perú.

Martínez I., Zuleta, R., Pacheco, A., Sanjines, J. (2007). Cooperación sobre el Lago Titicaca. División de Ciencias de Agua de UNESCO. https://hydrologie.org/BIB/Publ_UNESCO/TD_PCCP_032_S.pdf

Martínez L. A. (2018). Evaluación del estado de conservación de suelos contaminados por la relavera el Madrigal-Arequipa y propuesta de fitorremediación. [Tesis doctoral]. Universidad Nacional de San Agustín de Arequipa.

Ministerio del Ambiente [MINAM]. (2020). Guía ambiental para la disposición y tratamiento del agua producida. http://www.minem.gob.pe/minem/archivos/file/institucional/regionales/Publicaciones/GUIA\%20HIDROCARBUROS\%20I.pdf

Neff, J.M, Lee, K., Deblois, E. (2011). Produced water: overview of composition, fates, and effects. In: Lee, K. \& Neff, J. M. (Eds), Produced water environmental risk and advances in mitigation technologies. Springer. https://link.springer.com/chapter/10.1007/978-1-4614-0046-2_1

Newell, N.D. (1949). Geology of the Lake Titicaca region Peru and Bolivia. Geological Society of America, 36, 1-111https://doi.org/10.1130/MEM36

\begin{tabular}{|c|c|c|}
\hline 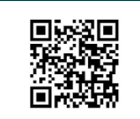 & (c) (1) & 194 \\
\hline
\end{tabular}




\section{Revista de CIENCIAS AMBIENTALES Tropical Journal of Environmental Sciences}
Revista de Ciencias Ambientales (Trop J Environ Sci) e-ISSN: 2215-3896
(Julio-Diciembre, 2021) . Vol 55(2): 180-196 DOI: https://doi.org/10.15359/rca.55-2.9 Open Access: www.revistas.una.ac.cr/ambientales e-mail: revista.ambientales@una.ac.cr Huisa D. y Loza-Del Carpio A.

Organismo de Evaluación y Fiscalización Ambiental [OEFA]. (2014). Reporte público de supervisión directa. Informe W 0074 -2013-OEFA/DS-HID. Ministerio del Ambiente, Perú.

Organismo de Evaluación y Fiscalización Ambiental [OEFA]. (2020). Derrame petróleo crudo, Perú. https://www.gob.pe/busquedas?institucion[]=oefa\&reason=sheet\&sheet=1\&term=derrame\%20petroleo\%20crudo

Ogbonna, J. F., Chinomso, A. (2009). Physicochemical characteristics and microbial quality of an oil polluted site in Gokana, Rivers State. Journal of Applied Sciences and Environmental Management, 13(3), 99-103. https://doi.org/10.4314/jasem.v13i3.55373

Ojimba, T. P. (2011). Economic effects of crude oil spillages on crop farms in Rivers State, Nigeria. Global Journal of Pure and Applied Sciences, 17(2), 131-136.

Peña-Salamanca, E. J., Madera-Parra, C. A., Sánchez, J. M., Medina-Vásquez J. (2013). Bioprospección de plantas nativas para su uso en procesos de biorremediación: Caso Helicona psittacorum (Heliconiacea). Revista de la Academia Colombiana de Ciencias Exactas, Fisicas y Naturales, 37(145), 469-481. https://doi.org/10.18257/raccefyn.29

PERUPETRO S.A. [PERUPETRO]. (2008). Titicaca Basin: Technical Report, The hydrocarbon potential of Titicaca Basin by geological - geophysical evaluation group exploration Management PERUPETRO https://www.perupetro.com.pe/wps/wcm/connect/corporativo/2d59463 1-e452-4aba-96cc-ce56322e261e/Titicaca\%2BFinal\%2B\%2B301208.pdf?MOD=AJPERES

Pestalozzi, H., Tórrez, M, Nina, J., Villca, C. (1998). Flora ilustrada altoandina: La relación entre hombre, planta y medio ambiente en el Ayllu Majasaya Mujlli. Herbario Forestal "Martín Cárdenas, Cochabamba, Bolivia.

Rodríguez-Eugenio, N., McLaughlin, M., Pennock, D. (2019). La contaminación del suelo: Una realidad oculta. FAO.

Romero-Lázaro, E. M., Ramos-Pérez, D., Romero F. M. \& Sedov, S. (2019). Indicadores indirectos de contaminación residual en suelos y sedimentos de la cuenca del Río Sonora, México. Revista Internacional de Contaminación Ambiental, 35(2), 371-386. https://doi.org/10.20937/ RICA.2019.35.02.09

Sabroso, M. C., Pastor, A. (2004). Guía sobre suelos contaminados. Confederación de la Pequeña y Mediana Empresa Aragonesa y Departamento de Economía, Hacienda y Empleo, Gobierno de Aragón. Zaragoza. https://www.academia.edu/29109561/ Gu\%C3\%ADa_sobre_suelos_contaminados

Salmerón, A., González, A., Barbán, L., Álvarez, L. O. (2015). Abundancia y diversidad de plantas leñosas en áreas de bosques semideciduos micrófilos, sometidos a diferentes niveles de

\begin{tabular}{|c|c|c|c|c|c|}
\hline 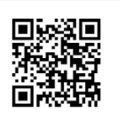 & (c) (i) () & $\underbrace{}_{\text {AMBIFNAIIES }}$ & $\begin{array}{l}\frac{9 \%}{2} \\
\frac{2}{2} \\
\text { euna }\end{array}$ & 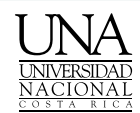 & 195 \\
\hline
\end{tabular}




\section{Revista de CIENCIAS AMBIENTALES Tropical Journal of Environmental Sciences}
Revista de Ciencias Ambientales (Trop J Environ Sci) e-ISSN: 2215-3896
(Julio-Diciembre, 2021) . Vol 55(2): 180-196 DOI: https://doi.org/10.15359/rca.55-2.9 Open Access: www.revistas.una.ac.cr/ambientales e-mail: revista.ambientales@una.ac.cr Huisa D. y Loza-Del Carpio A

perturbaciones antrópicas. Foresta Veracruzana, 17(2),11-20. https://www.redalyc.org/jatsRepo/497/49743956002/index.html

Schlumberger del Peru S.A. [SCHLUMBERGER] (2020). Explorando las profundidades del Perú. http:// www.minem.gob.pe/minem/archivos/Viaje\%20hacia\%20el\%20interior\%20de\%20la\%20tierra.pdf

Servicio Nacional de Meteorología e Hidrología Del Perú [SENAMHI]. (2015). Monitoreo de temperaturas y precipitación. https://www.senamhi.gob.pe/?\&p=descarga-datos-hidrometeorologicos

Sepúlveda, B. A., Pavez, O., Tapia, M. (2013). Uso de Salicornia sp. en la fitorremediación de relaves. XXV Encontro Nacional de Tratamento de Minérios e Metalurgia Extrativa \& VIII Meeting of the Southern Hemisphere on Mineral Technology, Goiânia.

Shrivastava, P., Kumar, R. (2015). Soil salinity: a serious environmental issue and plant growth promoting bacteria as one of the tools for its alleviation. Saudi Journal of Biological Sciences, 22(2), 123-131. https://doi.org/10.1016/j.sjbs.2014.12.001

Shrestha, B., Lipe, S., Johnson, K.A., Zhang, T.Q., Retzlaff, W., Lin, Q. (2006). Soil hydraulic manipulation and organic amendment for the enhancement of selenium volatilization in a soil-pickleweed system. Plant Soil, 288,189-196. https://doi.org/10.1007/s11104-006-9107-2

Trujillo-Narcía, A., Rivera-Cruz, M. C., Lagunes-Espinoza, L.C., Palma-López, D.J., Soto-Sánchez, S., Ramírez-Valverde, G. (2012). Efecto de la restauración de un fluvisol contaminado con petróleo crudo. Revista Internacional de Contaminación Ambiental, 28(4), 361-374. http://www.scielo.org.mx/scielo.php?pid=S0188-49992012000400011\&script=sci_abstract

Tropicos. (2020). Tropicos.org. Missouri Botanical Garden. http://www.tropicos.org

Tuset, S. (2020). Tratamiento de salmueras en extracción de petróleo. Condorchem Envitech. https://blog.condorchem.com/tratamiento-de-salmueras-en-extraccion-de-petroleo/

Vargas, L. (2002). Evaluación de la diversidad de flora silvestre en tres comunidades del distrito de Capachica - Puno [Tesis de Licenciatura]. Universidad Nacional del Altiplano Puno. http://repositorio.unap.edu.pe/handle/UNAP/15653

Velásquez, J. A. (2017). Contaminación de suelos y aguas por hidrocarburos en Colombia, análisis de la fitorremediación como estrategia biotecnológica de recuperación. Revista de Investigación Agraria y Ambiental, 8(1),151-167. https://doi.org/10.22490/21456453.1846

Voijant, B. T., Rozaimah, S. S., Basri, B., Idris, M., Anuar, N., Mukhlisin M. (2011). A review on heavy metals (As, $\mathrm{Pb}$, and $\mathrm{Hg}$ ) uptake by plants through phytoremediation. International Journal of Chemical Engineering, 2011, 1-31. https://doi.org/10.1155/2011/939161

Yavari, S., Malakahmad, A. \& Sapari, N. B. (2015). A Review on phytoremediation of crude oil spills. Water Air \& Soil Pollution, 226(279). https://doi.org/10.1007/s11270-015-2550-Z

\begin{tabular}{|c|c|c|}
\hline 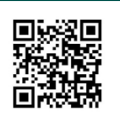 & (c) (i) () (2) & 196 \\
\hline
\end{tabular}

